\title{
Key Issues in Fuertes-Olivera and Tarp's Theory and Practice of Specialised Online Dictionaries
}

\author{
Valeria Caruso, Department of Literary, Linguistic and Comparative \\ Studies, University of Naples 'L'Orientale', Naples, Italy \\ (vcaruso@unior.it)
}

\begin{abstract}
Fuertes-Olivera and Tarp's Theory and Practice of Specialised Online Dictionaries is a long-awaited volume, offering a systematic description of the tenets of function theory. The authors present this theoretical framework both as a guideline in order to accomplish different lexicographical tasks (i.e. from compiling dictionaries to assessing the lexicographical suitability of other theoretical models), and as a valuable methodological tool which can be used to detect the users' needs. The 'Functional approach' is thus considered to be an alternative method to the research on users' behaviour. However, not only the new ideas and the terminology used within this field of lexicographical research deserve attention, but also some issues related to the concept of specialised lexicography, which are briefly outlined by Fuertes-Olivera and Tarp in the book. Their definition of this sub-discipline stimulates further reflections on the epistemic status of the two branches of lexicography (general and specialised) as well as on the related concepts of general and cultural knowledge.
\end{abstract}

Keywords: DICTIONARY CRITICISM, ENCYCLOPAEDIAS, SPECIALISED KNOWLEDGE, SPECIALISED LEXICOGRAPHY, LEXICOGRAPHICAL THEORY, ONLINE DICTIONARIES, PROSCRIPTION

Opsomming: Sleutelkwessies in Fuertes-Olivera en Tarp se Theory and Practice of Specialised Online Dictionaries. Daar is lank gewag vir Fuertes-Olivera en Tarp se Theory and Practice of Specialised Online Dictionaries — 'n boek wat 'n sistematiese beskrywing bied van die beginsels van die funksieteorie. Die skrywers bied hierdie teoretiese raamwerk sowel as 'n riglyn om verskillende leksikografiese take uit te voer (van die samestelling van woordeboeke tot by die beoordeling van die leksikografiese gepastheid van ander teoretiese modelle) as 'n waardevolle metodologiese instrument wat gebruik kan word om gebruikersbehoeftes vas te stel. Die funksionele benadering word dus beskou as ' $n$ alternatiewe metode tot navorsing oor gebruikersgedrag. Dit is egter nie net die nuwe idees en terminologie wat in hierdie veld van die leksikografie gebruik word wat aandag verdien nie maar ook sekere kwessies verwant aan die begrip van vakleksikografie wat kortliks deur Fuertes-Olivera en Tarp in hierdie boek aangebied word. Hulle definisie van hierdie subdissipline stimuleer verdere nadenke oor die epistemiese status van die twee vertakkings van die leksikografie (algemene en gespesialiseerde) asook oor die verwante begrippe van algemene en kulturele kennis.

Sleutelwoorde: AANLYN WOORDEBOEKE, ENSIKLOPEDIEË, GESPESIALISEERDE KEN- 
NIS, LEKSIKOGRAFIETEORIE, PROSKRIPSIE, VAKLEKSIKOGRAFIE, WOORDEBOEKKRITIEK

\section{Tools and Functions to overcome division}

Theory and Practice of Specialised Online Dictionaries, published this year by De Gruyter, is presented by the authors, Pedro A. Fuertes-Olivera and Sven Tarp, as a compendium of the lexicographical research carried out within the tenets of the function theory. Reminiscent of its antecedent, the Manual of Specialised Lexicography, the authors underline how 20 years of advances in the field have necessitated an up-to-date report on the theoretical assumptions that in 1995 were still in their infancy. However, not only the theory, but also the actual activity of compiling dictionaries has increased enormously ever since, in terms of both quantity (with more than one hundred vocabularies published) and quality. In this regard, the collaboration between the Centres for Lexicography in Aarhus (Denmark) and in Valladolid (Spain) is recognised as one of the most significant contributions to have enhanced the development of lexicographical theory and practice, and two representatives of these institutions have consequently written this comprehensive volume about the function theory of lexicography.

The book opens (Chapter 1: Introduction, and Chapter 2: What is Specialised Lexicography?) with historical notes explaining the origins of what the authors consider to be the first "schism" in lexicography: the strict division between dictionaries describing general language, and those explaining "things", namely specialized dictionaries and encyclopaedias. According to Fuertes-Olivera and Tarp, Samuel Johnson is responsible for this division. The British lexicographer seems to have deliberately excluded from the preface to the Dictionary of the English Language any assertion regarding the fact that dictionaries could also deal with 'things', on the contrary, he remarked the fact that they are 'wordbooks'. However, in the 18th century other authors, such as John Harris and Jean le Rond D'Alembert, affirmed that dictionaries could portray terms and sciences as well. Therefore, the dictionary was considered to be an organizing format suitable for whatever kind of knowledge it was required to convey.

In fact, this same idea is one of the main assumptions of the lexicographical function theory, as is stated more clearly elsewhere by Tarp:

[t]he truly unique thing about dictionaries is not the various types of data they employ in covering the information needs of users [...]. Such data can generally be incorporated into other types of book and text as well. The truly unique thing is the way in which this data is made accessible so users can quickly and easily find the exact data they need. (Tarp 2008: 101)

The way dictionaries allow users to get quickly to the required data is, thus, the true focus of lexicography, regardless of the nature of the information itself. Data access and a broader reference science ('accessology') were thus (Tarp 2008) advocated as the necessary step forward to update lexicography accord- 
ing to the requirements of the new information society. In fact, the broad concept of 'accessology' has inspired much research and many papers in the field of function theory (Bergenholtz and Gouws 2010; Leroyer 2011; Fuertes-Olivera and Niño-Amo 2011, to quote but a few), but it has also caused scepticism outside the realm of this paradigm of studies. Lew (2008), for example, maintained that lexicography should preserve its purview, and should not morph into a wider reference science.

Theory and Practice of Specialised Online Dictionaries approaches the matter from a different angle, with reference to the same topic of broadening the field of lexicography in order to compile dictionaries that, by taking advantage of the new information technologies available, would allow users to satisfy their information needs more easily. Fuertes-Olivera and Tarp choose in fact to discuss critically two epistemic distinctions which have traditionally characterised lexicography. The first is the above mentioned opposition between general and specialised dictionaries, the other is a sub-field discernment regarding the discriminative features of encyclopaedias and specialised dictionaries. Of the two, only the second proves to be inconsistent, while the other is eventually upheld by the authors.

The distinction between general and specialised dictionaries is in fact taken as a starting point to dismantle the confusing labels applied to different types of dictionaries on the basis of their specialisations. This descriptive approach produces an incongruous metalexicographical terminology, since there are too many labels used for naming specialised dictionaries, which are nonetheless still insufficient to cover the huge variety of available resources, i.e. specialised dictionaries, LSP dictionaries, technical dictionaries, terminological dictionaries or, lastly, special dictionaries. On the contrary, Fuertes-Olivera and Tarp apply their usual method of abstraction to multi-faceted real objects and decide to adopt the traditional distinction between 'general' and 'specialised' lexicography, which is based on the kind of knowledge dealt with in dictionaries (i.e. general or specialised). The choice proves to be advantageous from a practical point of view, explaining for example why dictionaries of collocations (or with other linguistically-restricted coverage) should not be called 'specialised'. At the same time, this juxtaposition is used to formulate the following statement:

specialised lexicography is here defined as the branch of lexicography concerned with the theory and practice of specialised dictionaries, i.e. dictionaries, encyclopaedias, lexica, glossaries, vocabularies, and other information tools covering areas outside general cultural knowledge and the corresponding Language for General Purposes (LGP). (7)

The distinction between "general cultural" and "specialised knowledge" is presented as intuitive and uncontroversial, thus it is not elaborated on. The only additional notation provided regards the fact that their opposition is purely transitional, since it is impossible to grasp precise divisions between the realm of specialised and general knowledge. Therefore, no clear-cut divisions can be 
outlined between these two blurred categories, which overlap in a grey area. This explanation partially builds a bridge between specialised and language dictionaries, a point that is subsequently clarified in the book, with a specific call for lexicographical theory to focus on the common features of dictionaries, rather than emphasising their bewildering differences. ${ }^{1}$

However, it must be admitted that a definition of the kind " $\mathrm{X}$ is what $\mathrm{Y}$ is not" ("tools covering areas outside general cultural knowledge and the corresponding Language for General Purposes") is rather inelegant and, since the categories involved are transitional, a set of relevant features would have probably been more suited to outline the unstable boundaries of specialized lexicography. On the other hand, it must be acknowledged that 'general knowledge', as well as Language for General Purpose are rather indefinite concepts, which derive from their counterparts, i.e. 'specialized knowledge' and Language for Special Purposes. The opposite is true of the definition provided by Fuertes-Olivera and Tarp, which derives specialised knowledge from the most unclear concept in the discussion, i.e. general knowledge.

This last notion is surely worthy of further analysis, together with the role assigned by the function theory to linguistic facts in its general framework, and with respect to the general lexicography (as opposed to the specialised lexicography). Readers, like myself, might also be puzzled by the role of language provided in the epistemic division, which distinguishes between general and specialised languages, paralleling general and specialised knowledge.

\section{Language and lexicographical descriptions within the framework of function theory}

From a careful reading of this book and others (Tarp 2008), however, some relevant explanations can probably be collected. Language, in fact, proves to encompass two different ontological statuses in function theory. On the one hand, it is a skill (52-54 and Tarp 2008: 131-136), allowing native speakers "to communicate with other speakers of the same language". On the other, it is a specific kind of knowledge, namely a "learned knowledge of the language" consisting of a "conscious, systematic knowledge" of one language, which allows people to explain "the precise meaning of individual words or to formulate the grammatical rules which they are unconsciously automatically able to use" (Tarp 2088: 133). In Lexicography in the Borderland between Knowledge and Nonknowledge, Tarp clearly explained that "in a living language vocabulary and grammar do not have their own independent existences" (Tarp 2008: 135), but Linguistics can help a lot since, using abstraction, this science is able to separate and examine each of them, and the

knowledge resulting from this examination can be communicated in connection with the study of a foreign language. This communication can take place by teaching, by the autonomous study of textbooks and grammar books, and by consulting dictionaries. (Tarp 2008: 135) 
This explanation offers clear evidence regarding the fact that the Language for General Purpose is a set of metalinguistic generalizations (named by Tarp 2008 'language knowledge') about the grammar and vocabulary used by people belonging to different professional groups in everyday life and interaction, to convey general cultural concepts. The features of this knowledge-oriented description of one language are dealt with in general dictionaries, and they should be identified, as the previous quotations suggest, on the basis of abstraction, using pertinent theories (mainly belonging to the branch of Sociolinguistics, one assumes). It is, therefore, not out of place to cite here one particular area of Linguistics research, carried out in Italy by Tullio de Mauro in the 60s and currently undergoing revision in order to be updated (De Mauro and Chiari 2014).

The aim of this investigation (De Mauro 2004) was to portray the 'basic vocabulary' of the Italian language, namely the minimal inventory of words that are necessary to cover the basic understandings of ordinary life. The research was carried out in order to promote the simplification of bureaucratic language and official texts used in public communication. Results were thus published in the form of a prescriptive wordlist, recommended to be used when compiling official documents, which should be able to be understood by everyone. The project was therefore intended to identify the bulk of the Language for General Purpose of a linguistic community, representing its general cultural knowledge as well. The methodology employed for this project is therefore interesting and relevant also for our discussion, highlighting the kind of problems posed by this type of language delimitation, as well as the procedures adopted to overcome them. Firstly, the concept of 'basic vocabulary' was quantified in terms of the amount of words that are mastered by native speakers with a primary school qualification, i.e. 8 years in the educational system of the country. This led to a selection of approximately 7200 words, the majority of which were derived from the list of the 5000 highest-frequency words of a corpus, reduced to 4750 after a comprehension test administrated to Italian speakers with a primary school qualification, both adults and children. The remaining 2300 items are instead 'highly available' words, or words that are rarely used, like the names of common tools (e.g. wipers or mops), albeit they belong to everyday life and thus are part of our general cultural knowledge. They were not extracted by corpora, but were chosen from dictionaries and interviewing different groups of people. Despite the fact that no dictionary would be really useful if it contained only the lemmas that everyone already knows ('basic vocabulary'), the study shows some methods in Sociolinguistics research integrating various approaches (from corpora to interviews and tests) in order to overcome some issues related to the concept of general language and common knowledge. Lastly, the 'basic vocabulary' of one language represents a useful repository of words for writing definitions that everyone can understand.

Going back to the role that linguistic aspects play in lexicographical descriptions according to function theory, it may be inferred from the previous 
discussion that language is the topic of lexicographical description as long as it is useful to support the intended users with the tasks for which the dictionary is compiled. In fact, language per sé is not at the forefront of the discussion, but its content-related counterparts, i.e. the Language for General or for Special Purposes. For example, collocations and grammar notes should be offered in specialised dictionaries when support with communicative tasks is required, as is shown in Chapter 9 of the book. Likewise, different levels of linguistic descriptions require appropriate theoretical solutions and, thus, the proper metalinguistic analysis, in order to comply with the intended aim of the dictionary, e.g. to describe the history of one language, its contemporary use and forms, or learning one language for native or non-native speakers (26).

\section{Typological and evaluative classifications of dictionaries}

As the previous discussion highlights, the content-dependent interpretation of linguistic facts (general and specialised language) also dismantles the other troublesome dispute in lexicography presented in the first pages of the book, namely the "Chinese wall" between LSP dictionaries and encyclopaedias. In fact, the authors maintain that specialised lexicography "by far transcends a mere description of the various specialised languages and also treats the very substance of these disciplines themselves in order to provide direct, punctual access to their cognitive achievements" (8). Therefore, the "Chinese wall" traditionally raised between more linguistically-oriented tools (commonly called 'LSP dictionaries') and those relying more heavily on the description of "things" (generally referred to as 'encyclopaedias') is actually inconsistent, provided that these reference works differ only in the type of support offered to users. While encyclopaedias have traditionally dealt with specific topics more extensively, in order to provide a "profound study of one or more subject fields" (12), dictionaries tend to offer more punctual information to assist with different, but more circumscribed tasks: e.g. translation or comprehension of one specific term, spellchecking, choice of the correct collocation. The authors underline that these various activities require different lexicographical solutions in order to be carried out, albeit the intrinsic nature of these tools remains the same. In addition to these arguments, based on the juxtaposition with other studies, the authors offer an illustrative metaphor taken from Diderot's (1755) preface to the French Encyclopédie, which illustrates the essence of specialised reference works that Fuertes-Olivera and Tarp have in mind. As the French Illuminist explains, the pioneering work of the Encyclopédie was meant to assemble "knowledge scattered over the face of the earth", making it available to all humankind for the purpose of improving education and, consequently, increasing happiness. The ethical standpoint offered by the illuminists, as well as the similarities with their visions and intents honour the lexicographical function theory with new arguments, shifting the focus on different aspects of the core idea of a broader reference science (elsewhere called 'accessology'), whose principles should 
inform its subordinated sub-disciplines. However, it must be underlined that this point is not at the forefront of discussion in Chapter 2, since it follows the long presentation of the many epistemic boundaries that prevent a radical shift in the field of lexicography. In this respect, Theory and Practice of Specialised Online Dictionaries adopts a more moderate view, avoiding a discussion of the more general and "provocative ideas" (Fuertes-Olivera and Bergenholtz 2011: vii) of function theory, such as the above-mentioned topic of "accessology", which receives an indirect mention only by quoting Henriksen's (1992) "referensology" (8).

On the contrary, many other topics of function theory are re-proposed in the volume, and some have also been enriched by additions and new details. This is the case, for example, with the evaluative typology of electronic dictionaries, which elaborates on some earlier proposals by Tarp $(2011,2012)$, adding one grade in the evaluation scale, i.e. "Stray Bullets" dictionaries.

These tools, in fact, can be divided into five groups, depending on the kind of support they offer to users, with respect to the technology employed. The assessments range from very poor resources, which are online reproductions of printed editions by means of scans or photographs (Copycats), to the adaptive (Gamper and Knapp 2002) tools of tomorrow, called "Rolls Royces", which should be able to customize themselves according to the user's needs. At the lower end of the scale, there are the "Faster Horses", tools improving paper dictionaries because some search facilities have been added, and the "Stray Bullets", which misuse technology since they do not know exactly what to do with it. In fact, some of these dictionaries make information drop behind the fancy use of technology, transforming the dictionary in an entertaining device (called "lexicotainment" by Almind, Bergenholtz and Vrang 2006). Some others, however, customize their entries in terms of the amount of data displayed, instead of tailoring the kind of information provided on the basis of the user's needs. Both these tools are far from achieving any of the qualitative improvements that are expected to take place in electronic lexicography, and have already begun to become reality, in the view of the authors, with "Model TFord" dictionaries, a label named after the revolutionary car produced by Henry Ford. These resources actually allow users to set the entries according to their expertise level, and the specific task to be fulfilled. Among the first tools provided with these functionalities, one can list the "monofunctional" dictionaries of the Diccionarios de Contabilidad, edited by the International Centre for Lexicography at the University of Valladolid, and the Centre for Lexicography at Aarhus University.

\section{Theoretical status of lexicography and some academic partitions}

Chapter 3 (Academic Status of Specialised Lexicography) and 4 (Concept of Lexicographical Theory) explain why lexicography is an independent science with its own theories. 
The discussion moves from evidence regarding the fact that, despite the huge variety of reference works produced over the centuries, there is an intuitive understanding that all of them are lexicographical products. This highlights the fact that some common features should exist, and they are independent from the specific data contained in every single dictionary, thus proving that contents (or data) and containers ${ }^{2}$ (dictionaries or whatever other organizing tool) conduct separate lives. Having considered these matters, lexicography should be independent from any other discipline, in order to promote its own theories and principles for a better production of the ordered containers of knowledge that are commonly called dictionaries. Further proof is also provided to sustain this independence.

First of all, the authors affirm that no reflections inspired by theories in Linguistics have proved to be of any assistance to the solution of real lexicographical problems. On the contrary, experts in one subject field, who were unacquainted with Linguistics, have in fact produced many excellent specialised dictionaries, such as Postlethwayt's and Savary des Bruslons' Economics dictionaries in the 18th century. Linguists have instead collaborated on lexicographical projects that are basically "conceived with a view to documenting a language" (26), however with different aims such as "assisting text reception, production and translation", or "supporting the acquisition of a first and second language". Fuertes-Olivera and Tarp admit that there are "excellent lexicographical works" among these, "yet all of them can undoubtedly be improved" (26). What the authors seem to complain about is the innate blindness of linguists, who are unable to discern between the topic of their lexicographical descriptions (i.e. the language) and the hosting tool (i.e. the dictionary), which is intrinsically different from the other, since it serves other purposes (the best presentation of data to the user). In addition, academic debates are also rendered even more complicated by the presence of terminologists, who claim to be the authorities in the description of terms using terminography. Therefore, those defending a lexicographical theory put into question the balance of stable partitions: linguists compile general language dictionaries, and terminographers edit terminology resources. These divisions prevent from a more congruous combination of disciplines that, according to Fuertes-Olivera and Tarp, should merge Information Science and Lexicography on the basis of their common major concern: how to retrieve information. Fruitful collaborations have already begun within the tenets of function theory, concerning "needs-adapted data presentation in e-information tools" (32), and the reconsideration of a key topic in Information Science like 'relevance', whose concept has been put into question by the lexicographical theory (Bothma and Tarp 2012).

An extended discussion of the theoretical status of lexicography is presented in Chapter 4. Within these pages, the authors demonstrate why lexicography is a science, contrary to the claims of other lexicographers and metalexicographers, who have expressed disbelief or maintained their positions with more detailed statements. The essential points in the debate focus on the fact 
that lexicography is a practical activity dealing with the creation of utility tools. Bejoint (2010) has thus questioned, "How can there be a theory of the production of artefacts?", since a theory is assumed to describe natural phenomena. Others, like Bogaards, have asked instead for a falsifiable method, i.e. the fact that every hypothesis ought to be verified in order to be scientific. FuertesOlivera and Tarp argue that both positions point to the paradigms of natural (in the case of Bejoint) and hard sciences (with respect to Bogaards), while it is undeniable that many scientific and academic disciplines belong to social phenomena which comply with different laws and principles, and these sciences are generally referred to as 'social sciences'.

Moreover, a theory is needed as long as the practical activity, i.e. compiling dictionaries, needs to be qualitatively improved, something which is possible only by means of sound guiding principles. With respect to these assumptions, the authors derive their epistemological model from the philosophy of science, which conceives theory as an "organised set of statements about an area of objective reality" (37), aiming to demonstrate the similarities among different objects as well as their relationships. Thus, theory is mainly an exercise in abstraction, which can nevertheless be applied at different levels like, for example, the "whole discipline" (general theories) or only "a restricted subarea" (specific theories). These generalizations may also be part of a general theory (integrated theories) or not (non-integrated theories); they may finally be purely descriptive of existing practices (contemplative theories) or, contrarily, they may be the guidelines for future developments (transformative theories; 38). The lexicographical function theory, making abstractions from the millenary dictionary practices, has eventually formulated its theoretical statements, which portray the essence of the lexicographical activity and thus are able to display the guidelines to improve dictionaries.

\section{Key concepts in function theory}

The well-known statement defining a 'lexicographical function' is offered again and again in the book using different formulations, whilst it is framed in its usual terms in Chapter 5 (General Theory of Specialised Dictionaries). Here the authors explain that a "lexicographical function", or the function that every dictionary should fulfil, consists in "the satisfaction of the specific types of punctual information need that may arise in a specific type of potential user in a specific type of extra-lexicographical situation" (64). This chapter is the most relevant in the book, presenting the main tenets of the theoretical paradigm, and stating more explicitly some of its most innovative, and unconventional methodologies. Basically, lexicographical functions are presented as a method used to detect users' needs, and the "Functional approach" is listed among other possible approaches to this topic: "Business as usual", "Personal knowledge", "User research" (46). Contrary to the practical investigations on users' behaviour (like questionnaires, protocols, or tests), lexicographers working 
within the functional approach deduce the users' needs in collaboration with field experts. This task is accomplished by profiling the relevant characteristics of users, which are identified on the basis of pre-set general questions as well as on the direct experience of one professional who is an expert in the same specialised field of the dictionary. Additionally, the perspective situations ( $\operatorname{Cog}$ nitive, Operative, Interpretative plus Communicative) in which the dictionary is used allow the lexicographer to define the kind of data to be included in the reference work. A detailed exemplification of this "pre-compilation phase" for a specialised translation dictionary is offered in section 5.5. The necessary steps for transferring one text in one target language are carefully discussed, thus highlighting the many parts of this process in which monolingual instructions (both in the source and target language) are needed, such as a general introduction on the subject matter. In accordance with this analysis, the overall lexicographical design of dictionaries for specialised translations is outlined, using different component parts for L1-L2 translations and L2-L1 respectively. In addition, Fuertes-Olivera and Tarp discuss the dictionary part (e.g. the L1-L2 bilingual part or the monolingual section) in which different types of data should be included (e.g. collocations or grammar notes), since data distribution is another relevant topic regarding the reduction of information overload, which is a prerequisite for satisfying users' needs.

In fact, too much data make dictionary consultation inefficient and eventually make a search ineffective. This should be the major concern of lexicographers, as Fuertes-Olivera and Tarp argue, especially in the current Internet era, since the electronic environment offers solutions to tailor the entries according to the users' needs (97). For example, the tenets of function theory have guided researchers to compile "monofunctional" dictionaries, tools that are customised on the basis of the desired function, thus displaying different kinds of data if users need to write a text or, for example, understand a specific term. Displaying different kinds of entries is possible in the electronic environment, because data are stored in databases and retrieved by interfaces that filter them according to the specific consultation situation; e.g. inflected forms for writing and translating, "usage and/or contrastive notes" to lemma for a better understanding of terms (212). A detailed exemplification of the features of these innovative tools, corresponding to Model T-Ford in the evaluative classification of section 2.3, is given in the last chapter of the book.

The revolutionary aspect of these dictionaries is not limited to the employment of technological solutions, but to the achievements obtained using these new means, which allow users to select data more effectively, thus making it easier to transform them into information, a necessary cognitive process for a successful fulfilment of information voids. Thus, two interrelated factors are involved, "comprehension-related" and "search-related information costs" (142), which will also be used by the authors as assessment parameters in the critical overview of online specialised resources presented in Chapter 8.

Before dealing extensively with the actual solutions for editing a new class 
of efficient dictionaries, in Chapter 9, Fuertes-Olivera and Tarp reflect more extensively on the lexicographical process, sketching their component parts both from the lexicographer's and the user's perspective.

While the first consists in three different compilation steps (pre-compilation, compilation, and post-compilation phase), the other is divided into an "extra-lexicographical pre-consultation phase", an "intra-lexicographical consultation phase", and an "extra-lexicographical post-consultation phase". Studies on dictionary use have mainly focused on the second, the intra-consultation phase; however the other two steps are considered to be more interesting by the authors, if they are approached focussing on how the user behaves "in the middle of these processes".

These researches should be carried out not by means of questionnaires and interviews, but using specific methods for observing users while they decide to "start a lexicographical consultation" (93), or testing the information they are able to retrieve from the dictionary. The first kind of investigation seems too costly to be carried out with statistically relevant demographic methods. The other, instead, is deemed more affordable and probably even more relevant, since in this phase it is possible to find the "proof of the pudding", namely evidence about the possibility of retrieving information from one dictionary, thus proving the quality of one dictionary as well as the "relevance of a lexicographical theory" (94).

One final remark should be made on another corollary of the theory of lexicographical functions, namely "proscription", or the way the lexicographer must behave with respect both to data documentation and user needs. In fact, while recording all possible forms and variants of one data, such as the many possible spellings of a particular word, the lexicographer should also signal (or recommend) the best choice available. This prevents the users from carrying out ineffective searches, which would occur if the nonstandard variant was not attested in the dictionary (this happens in prescriptive vocabularies), and allows them to receive the necessary advice about the correct form to use.

Chapter 6 (Special Problems Related to Online Dictionaries) starts with a complaint about the unimaginative use of the new powerful technologies, imputing the poor advances in lexicography to the "focus on practical problems related to natural language processing", as well as on other peripheral issues, such as user research. The pages of this chapter are instead devoted to showing how the new Internet environment can be exploited to obtain "higher lexicographical quality with lower production time and costs" (97).

The first type of technological devices discussed are the systems for data filtering, which allow compilers to offer tailored entries according to the consultation needs of users. The first option available is thus represented by the above-mentioned "monofunctional" access to specific kinds of data, which change on the basis of the type of consultation situation (e.g. writing, translating etc.). This option is adopted by many tools developed by the Centlex of Aarhus, as well as by the Diccionarios de Contabilidad presented in Chapter 9. 
Filters, however, can tailor data even further, also taking into account the characteristics of the user, guiding him step by step with "interactive fill-in options" (99) to set the dictionary or, alternatively, giving him the chance to model the article by selecting the desired features.

The amount of data can be controlled also by adding information only when needed. Entries, for example, can initially display just a little information, such as indexes of contents or abstracts, as well as a few lines of text that can be expanded by means of "pop-up windows". The user may also be allowed to add his personal notes (e.g. synonyms) or, in other cases, additional material collected on the Web may be linked to one page, thus offering more information on one topic. In this respect, the authors are sceptical about the "automatic incorporation of data", which should always be validated by the lexicographer, in order to preserve the reliability of authored dictionaries. This involves a less optimistic view of possible future developments of lexicography, since the authors believe that only a semi-automatic generation of articles is possible. The entries may be pre-complied by automatically retrieved materials, and then human experts should validate them. External and uncertified data should be explicitly signalled, and offered only to skilled users. It is obvious, however, that data from controlled corpora are more reliable than others that sprout up on the Internet with no restrictions.

\section{Functions of function theory}

The following sections of the book, Chapters 7 to 9 , are real examples of how the theory can be productively used for different aims, such as evaluating other theoretical approaches or existing resources, as well as compiling real dictionaries. This part is thus a substantial integration of the first chapters, since the function theory is expected to be productive or, transformative, using the terminology adopted within this paradigm of studies. Therefore, the analysis of other competing models is one of the first concerns whilst presenting the actual application of function theory.

Chapter 7 offers, in fact, A Critical View of Terminography, reviewing five different theories belonging to this field of studies, from the General Theory of Terminology, promoted by Wüster, to the different knowledge engineering methods that deal with knowledge-based management systems. The aim of this revision is to prove how far these theoretical models are from the lexicographical approach supported by the authors, as well as the inadequacy of the terminological frameworks for a coherent lexicographical description of specialised languages.

The analysis is subsequently completed in the next chapter (An Analysis of Specialised Online Dictionaries), in which different specialised reference works are evaluated. Some of them have been compiled in accordance with the tenets of previously presented theories, such as the Communicative Theory of Terminology, by Cabré, which is the theoretical approach used for compiling the 
Genoma project, or the frame-based model by Martin and Faber, which was used for the EcoLexicon. The revision process is carried out on the basis of ten assessment criteria, an "open list" that can also be improved with additional parameters. The declared goal of this section is to equip the confusing practice of "dictionary criticism" with principles that can turn it into a legitimate branch of lexicographical theory, as advocated by Wiegand and Gouws among others. This theoretical shift would allow both real users to receive valuable advice on the utility of existing dictionaries, and lexicographers to improve their works, referring to relevant analysis to their activities.

Results of this long enquiry (one of the longest sections of the whole book) are summarised in a table (201), assessing every evaluation feature for each dictionary. Additionally, the main findings are discussed in a brief list, which highlights that these specialised resources tend to accumulate irrelevant data for the envisaged functions, they are seldom updated, and are compiled without the assistance of any expert. A similar discredit to the characteristics of specialised languages is demonstrated by the pedestrian application of the same methodologies used for the analysis of the general languages. The major disappointment of the authors regards the use of corpora, which frequently serve as substitutes for the knowledge of experts, for example with respect to the lemma selection or the writing of definitions.

\section{New tools in lexicography: examples from the Accounting Dictionaries}

Contrary to these practices, the lexicographical process used for compiling the Accounting Dictionaries or Diccionarios de Contabilidad is noteworthy. The tool is a joint project of the lexicographers of the Aarhus University and of the University of Valladolid in Spain. Its title reveals that it is made up of a combination of different "monofunctional" dictionaries, assisting with cognitive and communicative tasks (211) all kinds of possible users: experts and semi-experts in the field of accounting, but also translators, students and laypersons (210). Chapter 9 (Designing, Making and Updating Specialised Online Dictionaries) is devoted to the description of the project in every phase, in order to give evidence of how theory becomes practice, and which methodologies make this process come true. The process is reported in detail, and offers many interesting topics for debate, also for specialised translation studies, which unfortunately cannot be dealt with here. Thus, the reader is recommended to go to these pages in order to have a real insight into a lexicographical process conceived within the tenets of function theory. Only a brief mention of some of the phases of the process and its main features can be made.

Firstly, the authors discuss the fact that the success of any lexicographical project relies on adequate planning of the software architecture, which is designed by IT experts and lexicographers together. Then users' profiles and the perspective situation of use of the dictionary allow the lexicographer to sketch the types of data to include. 
Major problems of specialised dictionary projects may depend instead on the nature of the specialised language itself, like accounting terminology, which lacks conspicuous documentation and is not "very systematised" (214), since its jargon is used in daily working life and different accounting practices and rules are used all over the world and even within individual countries. Moreover, Spanish terminology is full of calques, loans and alternative possible translations of the English terms, while the language may also change with respect to different types of institutions, whether companies or non-profit organisations. The greatest concern of the Accounting Dictionaries was thus the selection of lemmas, which only in a small part were extracted from a corpus of three million words. The majority were instead selected from existing dictionaries, "institutionalised accounting texts", and "private texts" (215), using extensive reading, one assumes, since this aspect is not well explained. The reason for adopting this time-consuming procedure is that the habitual readers of these texts are also the prospective users of the dictionary, thus no other method seems adequate for the compilation of a lexicographical tool with sufficient terminology coverage. Additionally, the lemma list increases constantly and undergoes a continuous revision process, attesting new variants, synonyms or providing corrections. The measure of 500 new terms added in a period of eight months gives an idea of the ongoing nature of the work, something that is also possible because the dictionary is hosted in the digital environment and can be easily modified.

\section{Final remarks}

In conclusion, this book has only a few drawbacks, which do not call into question its relevance for lexicographical theory and practice. They regard the nature of the general lexicographical concepts that have been highlighted at the beginning of this review, with respect to the ideas of general language and general lexicography, in comparison with specialised language and specialised lexicography. These definitions have been proposed by the authors in order to make a brief abridgment to the field of specialised lexicography with a cursory definition, which would have required a more systematic analysis instead. The avoidance of referring to a broader reference science ('referensology' or 'accessology') has also made the dialectical continuity between the two sub-disciplines (general and specialised lexicography) probably less evident, whilst it has highlighted some residual part of the theoretical work that, in my opinion, remains to be done. The future research of lexicographical function theory, I believe, should deal also with the concepts of different types of languages (general and specialised) that lexicography describes, in order to become a complete, general theory of the discipline, not of a specific sub-field. Despite the fact that lexicographical theoretical principles remain the same, each language type (general and specialised) seems to entail different methodological solutions in order to satisfy the consultation needs of users. Therefore, the 
overall lexicographical theory should probably deal more extensively with the specific requirements of these languages: their epistemic component (i.e. general and specialised knowledge), their variability (regional, national, local), and the type of documentation attesting them, as is demonstrated in the final part of the book on the Accounting Dictionaries.

Lastly, I have not touched upon many other topics, not because they are less important or less instructive, but because they would have derailed the discussion. I am still curious about some revision of old linguistic concepts by the lexicographical function theorists, such as 'collocation': "an umbrella term for referring to combinations of signs, typically words, which contextualise the meaning of lemmas and equivalents" (232). I would also have liked to read a more detailed discussion about definitions, not only describing what has been done in the Accounting Dictionaries (218-223), but also about the key topic of how definitions can facilitate users to turn the dictionary data into information, and what features may allow the lexicographer to accomplish this difficult task.

However, since the issues are correctly stated, many key lexicographical topics are therefore, at least, easier to address. This is also rendered possible by the use of new terminology, introduced by different theorists of the lexicographical function theory, which appears to fulfil its role well.

\section{Notes}

1. "Nor should it take its point of departure in the differences that separate all these works in terms of their specific content, structure etc., but in the aspects and elements that unite them and are common to all of them". (39)

2. The 'container' metaphor is my proposal, and it is not used in the book by Fuertes-Olivera and Tarp.

\section{References}

Almind, R., H. Bergenholtz and V. Vrang. 2006. Theoretical and Computational Solutions for Phraseological Lexicography. Linguistik Online 27(2). [http://www.linguistik-online.de/27_06/ almind_et_al.html]

Bejoint, H. 2010. The Lexicography of English. Oxford: Oxford University Press.

Bergenholtz, H. and R. Gouws. 2010. A New Perspective on the Access Process Hermes. Journal of Language and Communication Studies 44: 103-127.

Bergenholtz, H. and S. Tarp (Eds.). 1995. Manual of Specialised Lexicography: The Preparation of Specialised Dictionaries. Amsterdam/Philadelphia: John Benjamins.

Bothma, T.J.D. and S. Tarp. 2012. Lexicography and the Relevance Criterion. Lexikos 22: 86-108.

De Mauro, T. 2004 (1980). Guida all'uso delle parole: parlare e scrivere semplice e preciso per capire e farsi capire. Rome: Editori riuniti.

De Mauro, T. and I. Chiari. 2014. Il vocabolario di base dell'italiano dal 1980 a oggi: metodi e risultati. The Sixteenth EURALEX International Congress ("The User in Focus"), EURALEX 2014, 
Bolzano/Bozen, Italy, July 15-19, 2014. Bolzano/Bozen: EURAC. Oral presentation.

Fuertes-Olivera, P.A. and H. Bergenholtz. 2011. Introduction: The Construction of Internet Dictionaries. Fuertes-Olivera, P.A. and H. Bergenholtz (Eds.). 2011: 1-16.

Fuertes-Olivera, P.A. and H. Bergenholtz (Eds.). 2011. e-Lexicography: The Internet, Digital Initiatives and Lexicography. London/New York: Continuum.

Fuertes-Olivera, P.A. and M. Niño-Amo. 2011. Internet Dictionaries for Communicative and Cognitive Functions: El Diccionario Inglés-Español de Contabilidad. Fuertes-Olivera, P.A. and H. Bergenholtz (Eds.). 2011: 168-186.

Gamper, J. and J. Knapp. 2002. Towards an Adaptive Learners' Dictionary. Brusilovsky, P., O. Stock and C. Strappavara (Eds). 2002. Proceedings of the International Conference on Adaptive Hypermedia and Adaptive Web-based Systems (AH2000), August 28-30, 2000, Trento, Italy: 311314. Berlin/New York: Springer.

Henriksen, P. 1992. Forholdet mellem encyklopedologi og leksikografi. Fjeld, R.V. (Ed.). 1992. Nordiske Studier i Leksikografi. Rapport fra Konferanse om leksikografi i Norden 28.-31. mai 1991: 219-227. Oslo: Nordisk Forening for Leksikografi.

Leroyer, P. 2011. Change of Paradigm: From Linguistics to Information Science and from Dictionaries to Lexicographic Information Tools. Fuertes-Olivera, P.A. and H. Bergenholtz (Eds.). 2011: 121-140.

Lew, R. 2008. Lexicographic Functions and Pedagogical Lexicography: Some Critical Notes on Sven Tarp's Lexicography in the Borderland between Knowledge and Non-knowledge. Iwan, K. and I. Korpaczewska (Eds.). 2008. Przeglad Humanistyczny. Pedagogika. Politologia. Filologia: 114-123. Szczecin: Szczecińska Szkoła Wyższa Collegium Balticum.

Tarp, S. 2008. Lexicography in the Borderland between Knowledge and Non-knowledge. General Lexicographical Theory with Particular Focus on Learner's Lexicography. Tübingen: Niemeyer.

Tarp, S. 2011. Lexicographical and Other e-Tools for Consultation Purposes: Towards the Individualization of Needs Satisfaction. Fuertes-Olivera, P.A. and H. Bergenholtz (Eds.). 2011: 5470.

Tarp, S. 2012. Online Dictionaries: Today and Tomorrow. Lexicographica 28(1): 253-268. 